\title{
THE MECHANISM OF SOMATIC ASSOCIATION IN COMMON WHEAT, TRITICUM AESTIVUM L. II. DIFFERENTIAL AFFINITY FOR COLCHICINE OF SPINDLE MICROTUBULES OF PLANTS HAVING DIFFERENT DOSES OF THE SOMATIC- ASSOCIATION SUPPRESSOR ${ }^{1}$
}

\author{
LYDIA AVIVI, ${ }^{2}$ MOSHE FELDMAN² AND WALTER BUSHUK \\ Department of Plant Science, University of Manitoba, Winnipeg, Canada
}

Received January 28, 1970

$T_{\text {associated in somatic cells (Feldman, Mello-Sampayo and Sears 1966). }}^{\text {HE homologous chromosomes of common wheat, Triticum aestivum L., are }}$ This somatic association is regulated by a gene system located on the chromosomes of homoeologous group 5, i.e., chromosomes 5A, 5B, and 5D, (FELdmaiv $1966,1968)$. The long arm of chromosome $5 \mathrm{~B}\left(5 \mathrm{~B}^{\mathrm{L}}\right)$ carries a gene which suppresses somatic association and thus tends to cause random distribution of homologues in the somatic nucleus. On the other hand, the short arm of chromosome $5 \mathrm{~B}\left(5 \mathrm{~B}^{\mathrm{s}}\right)$ and the long and short arms of chromosomes $5 \mathrm{~A}$ and $5 \mathrm{D}$ carry genes which promote somatic association. The effect of the somatic-association promoters is opposite to that of the somatic-association suppressor. Thus in common wheat there is a balance between the suppressor and the several promoters which determines the degree of somatic association that occurs.

Studies on the effect of the somatic-association genes in aneuploid wheat plants having different doses of chromosomes $5 \mathrm{~B}, 5 \mathrm{D}$, and $5 \mathrm{~A}$ have shown that this balance can be shifted in either direction (FeLDMAN 1966, 1968) by increasing the dose of suppressor or promoter or by deleting the suppressor or one of the promoters, with resultant reduction or enhancement of the degree of association between homologues in somatic cells. The feasibility of such shifts in balance provides an excellent means for the study of the control and mechanism of somatic association.

In a previous paper, Avivi, Feldman and Bushur (1969) reported that colchicine, when applied at interphase, suppressed the association of homologous chromosomes in root-tip cells of common wheat. Since any disruption of a cell function caused by colchicine indicates that this function is dependent upon the existence of microtubular proteins (WeIsen BERG, Borisy and TAYLOR 1968), we suggested that a microtubular protein plays a decisive role in the association of homologous chromosomes in somatic cells. Colchicine supposedly suppressed somatic association by disrupting the organization of these microtubules.

\footnotetext{
1 Contribution No. 221 from the Department of Plant Science, University of Manitoba, Winnipeg 19, Canada with financial assistance from the National Research Council of Canada.

2 Present Address: Section of Plant Genetics, The Weizmann Institute of Science, Rehovoth, Israel.

Genetics 65 : 585-592 August 1970.
} 
Microtubular protein makes up the fibrous component of the spindle system and has an active role in chromosomal movement and distribution (INOUE and Sato 1967; Ledbetter 1967; Adelman et al. 1968). Thus, it is plausible that the spindle system might be involved in positioning the homologous chromosomes near each other in the somatic nuclei. This possibility might also be expected from the fact that the centromere is the chromosomal region which is primarily responsible for the association of homologous chromosomes in somatic cells (FELDman, Mello-Sampayo and Sears 1966). Accordingly, the hypothesis has now been tested that the somatic-association genes regulate the degree of association of homologous chromosomes in somatic cells by affecting some of the characteristics of the spindle microtubules. Evidence is presented indicating that the spindle microtubules of plants having different doses of the somatic-association genes show differential affinity for colchicine.

\section{MATERIALS AND METHODS}

The in vivo sensitivity of spindle microtubules to the disruptive action of colchicine was studied in dividing root-tip cells of common wheat, Triticum aestivum L. Lines of the variety Chinese Spring having different doses of chromosomal arm $5 \mathrm{BL}^{\mathrm{L}}$ and $5 \mathrm{~B}^{\mathrm{S}}$ were used; the dosage of $5 \mathrm{~B}^{\mathrm{L}}$ and $5 \mathrm{~B}^{\mathrm{S}}$ in each line is listed in Table 1.

To verify that the seedlings had the specified dosage of chromosomal arm $5 \mathrm{~B}^{\mathrm{L}}$ or $5 \mathrm{~B}^{\mathrm{S}}$, counts of chromosome numbers were made in cells of most of the root tips studied. This was especially important in the progenies of di-isosomic $5 \mathrm{~B}^{\mathrm{L}}$, in which the dosage of $5 \mathrm{~B}^{\mathrm{L}}$, was different than four in about $20 \%$ of the seedlings.

The seeds were germinated in distilled and deionized water at room temperature $\left(22^{\circ} \mathrm{C}\right.$ $23^{\circ} \mathrm{C}$ ). After $48 \mathrm{hr}$, when the seminal roots were $1.0-2.0 \mathrm{~cm}$ long, the seedlings were transferred to Petri dishes $(5.0 \mathrm{~cm}$ in diameter) containing $2.5 \mathrm{ml}$ of colchicine solution of proper concentration. The colchicine solution treatment was for a period of four hours. For control, seedlings were held for the same period in $2.5 \mathrm{ml}$ distilled and deionized water. The colchicine was obtained from Nutritional Biochemical Corporation, and solutions were freshly prepared using distilled and deionized water. The following concentrations were used: $1 \times 10^{-4}, 2 \times 10^{-4}, 3 \times 10^{-4}$, $4 \times 10^{-4}, 5 \times 10^{-4}, 7 \times 10^{-4}, 1 \times 10^{-3}$, and $2 \times 10^{-3} \mathrm{M}$. After treatment, the root tips were severed and fixed, and squashes prepared by the aceto-carmine staining technique.

In each experiment, several hundred cells were examined. These cells were derived from five or more different seedlings that were treated in several separate experiments.

The effect of colchicine was examined only in those cells that were at the metaphase stage. The metaphase cell population was classified into three different categories (Figure 1):

TABLE 1

Dosage of chromosomal arm $5 B^{L}$ and $5 B^{S}$ in the four lines used

\begin{tabular}{|c|c|c|c|}
\hline & & \multicolumn{2}{|c|}{ Dosage } \\
\hline & Chromosomal constitution & $5 \mathrm{~B}^{\mathrm{L}}$ & $5 \mathrm{~B}^{\mathrm{S}}$ \\
\hline \multicolumn{4}{|c|}{ Lines with different doses of the suppressor } \\
\hline & Nullisomic $5 \mathrm{~B}$ tetrasomic $5 \mathrm{D}$ & 0 & 0 \\
\hline & Di-telosomic $5 \mathrm{~B}^{\mathrm{L}}$ & 2 & 0 \\
\hline . & Di-isosomic $5 \mathrm{~B}^{\mathrm{L}}$ & 4 & 0 \\
\hline \multicolumn{4}{|c|}{ Lines with different doses of the promoter } \\
\hline & Di-telosomic $5 \mathrm{~B}^{\mathrm{L}}$ & 2 & 0 \\
\hline & Disomic 5B & 2 & 2 \\
\hline
\end{tabular}




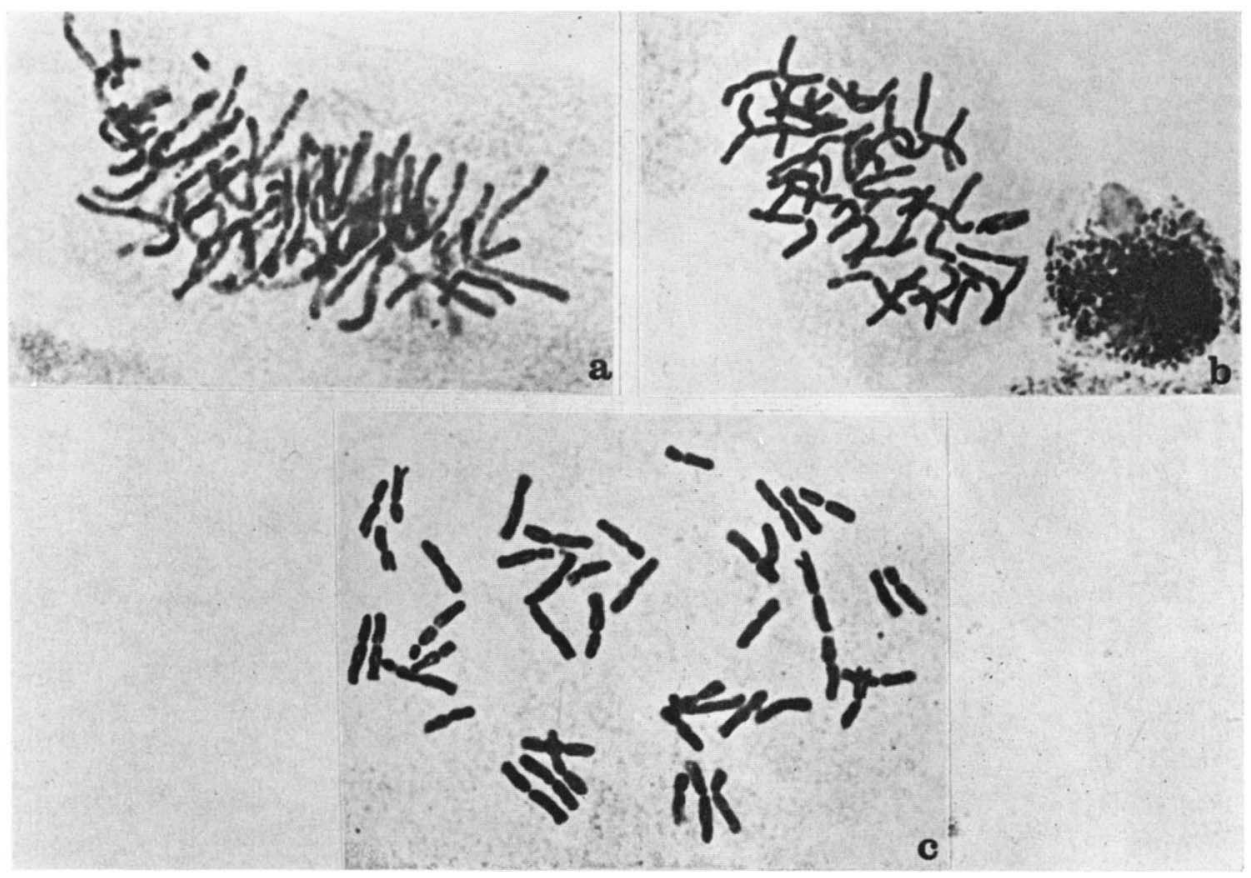

Figure 1.-Root-tip cells of common wheat in metaphase after treatment with colchicine. a.-Unaffected cell

b.-Partially affected cell

c.-Totally affected cell

1. Unaffected cells - their chromosomes were relatively long and were oriented with their centromeres on the equatorial plane, indicating normal development of the spindle (Figure 1A).

2. Totally affected cells - their chromosomes were in the form of typical C-pairs; that is, the sister chromatids of each chromosome underwent further shortening and were held together only at the region adjacent to the centromere. They were scattered throughout the cell, indicating complete suppression of spindle formation (Figure 1C).

3. Partially affected cells - their chromosomes exhibited only a slight to moderate degree of shortening, and their arrangement on the equatorial plane indicated initial or partial suppression of the spindle (Figure 1B).

The effect of each concentration of colchicine on the spindle was determined for each dosage of the somatic-association suppressor or promoter, and expressed as the percentage of the totally affected cells in the total metaphase cell population.

\section{RESULTS}

The results show clearly that the sensitivity of the spindle to colchicine decreased significantly when the dosage of the somatic-association suppressor was increased (Figure 2), and increased when the dosage of the somatic-association promoter was increased (Figure 3). Plants having zero doses of the suppressor, as in nullisomic $5 \mathrm{~B}$ tetrasomic $5 \mathrm{D}$, were most sensitive to colchicine. After treatment with concentrations as low as $2 \times 10^{-4} \mathrm{M}, 35 \%$ of the cells were totally affected. Maximum effect was observed at a concentration of $4 \times 10^{-4} \mathbf{M}$, where 


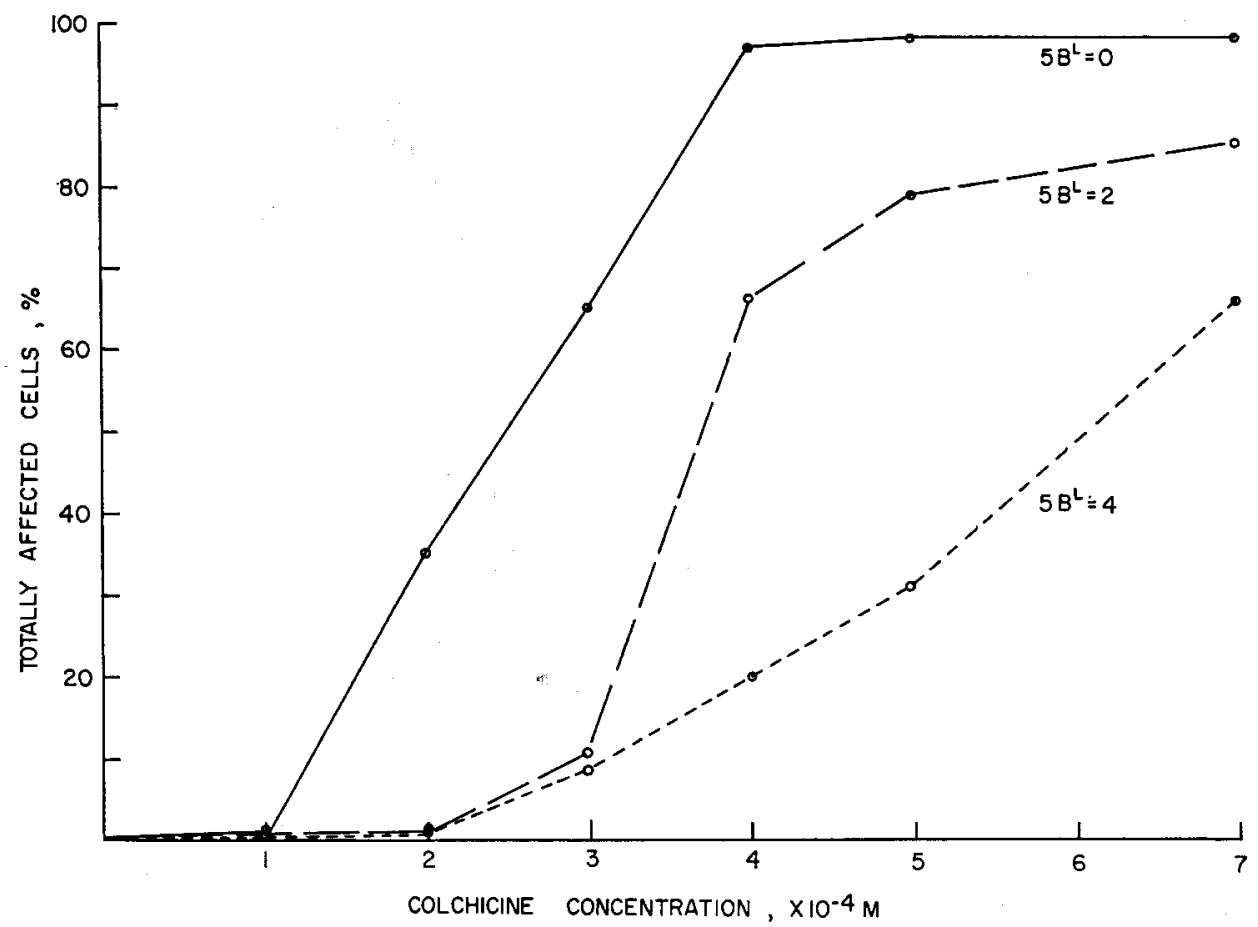

FIGURE 2.-Spindle sensitivity to colchicine as influenced by different doses of the somaticassociation suppressor (on chromosomal $\operatorname{arm} 5 \mathrm{~B}^{\mathrm{L}}$ ).

$97 \%$ of the cells were totally affected and the remaining $3 \%$ exhibited various degrees of partial spindle suppression.

Plants with two doses of the somatic-association suppressor, as in di-telosomic $5 \mathrm{~B}^{\mathrm{L}}$, were significantly less sensitive to colchicine. Totally affected cells begin to appear only after treatment with $3 \times 10^{-4} \mathrm{M}$ colchicine; while with a concentration as high as $7 \times 10^{-4} \mathrm{M}$ colchicine only $85 \%$ of the cells were totally affected.

The spindle of plants with four doses of the association-suppressor gene (diisosomic $5 \mathrm{~B}^{\mathrm{L}}$ ) was the least sensitive to colchicine. Here, although totally affected cells began to appear after treatment with $3 \times 10^{-4} \mathrm{M}$ colchicine, the sensitivity at higher colchicine concentrations was much lower than in plants having lower dosage of $5 \mathrm{~B}^{\mathrm{L}}$. After treatment with concentrations as high as $5 \times 10^{-4} \mathrm{M}$, only $31 \%$ of the cells showed full effect, and in $7 \times 10^{-4} \mathrm{M}$ only $66 \%$ of the cells were totally affected. Even higher concentrations of colchicine $\left(1 \times 10^{-3} \mathrm{M}\right.$ and $\left.2 \times 10^{-3} \mathrm{M}\right)$, did not increase above 66 the percentage of totally affected cells (Figure 2).

When plants with different doses of $5 \mathrm{~B}^{\mathrm{s}}$ were treated with colchicine, the spindle sensitivity was directly related to the dosage of the somatic-association promoter (Figure 3 ). In the range of colchicine concentrations studied (from $1 \times 10^{-4} \mathrm{M}$ to $7 \times 10^{-4} \mathrm{M}$ ), plants with two doses of $5 \mathrm{~B}^{\mathrm{S}}$, as in disomic $5 \mathrm{~B}$ plants, were always more sensitive than those with zero dose as in di-telosomic $5 \mathrm{~B}^{\mathbf{L}}$. 


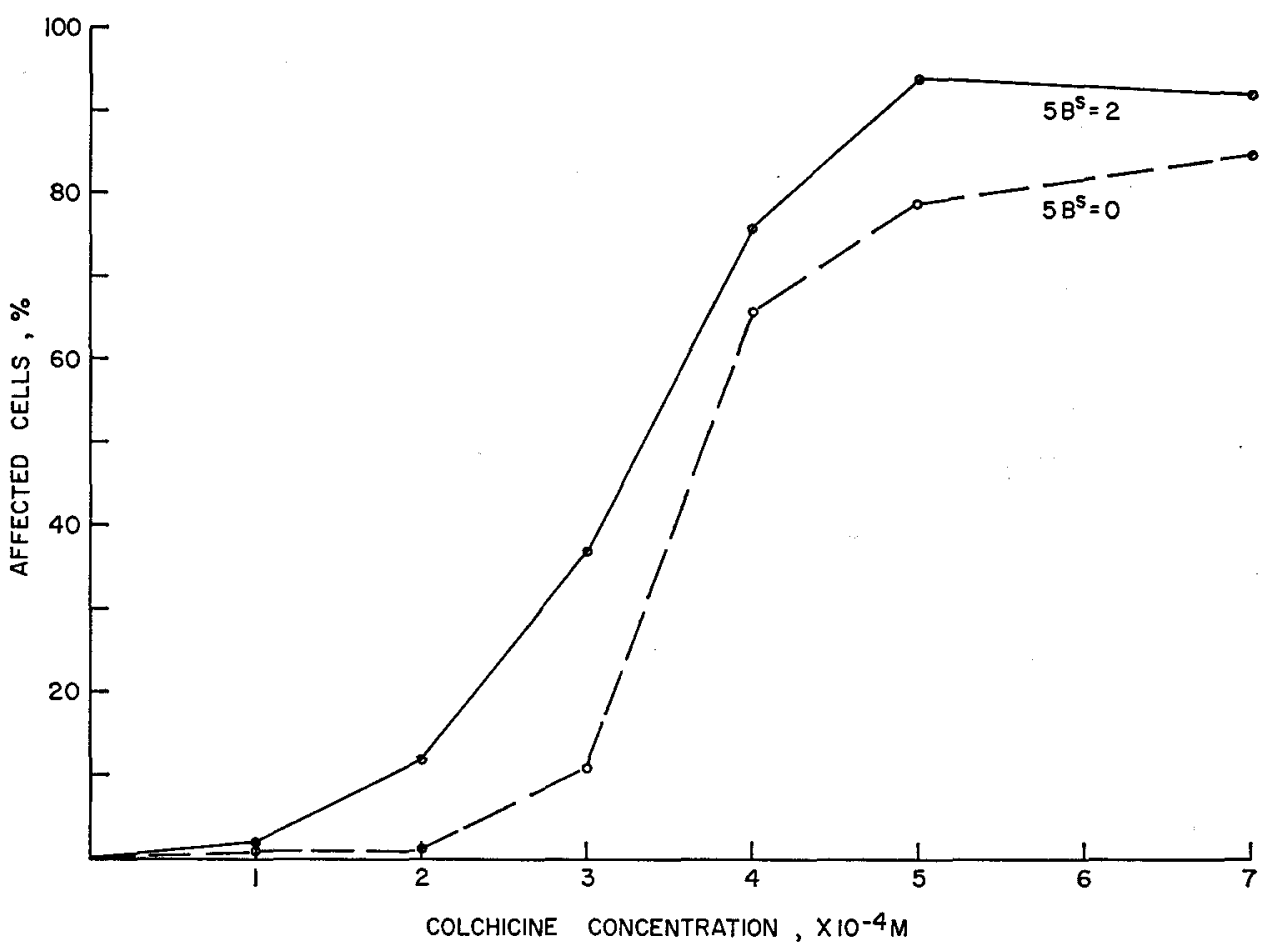

FIGURE 3.-Spindle sensitivity to colchicine as influenced by different doses of the somaticassociation promoter (on chromosomal arm $5 \mathrm{~B}^{\mathrm{S}}$ ).

It is of interest to note that graphs of spindle sensitivity versus colchicine concentration for plants having low (zero) or high (four) dosages of $5 \mathrm{~B}^{\mathbf{L}}$ are approximately linear. That is, the sensitivity of the spindle to colchicine in these plants depends directly on the amount of colchicine until all the cells are totally affected. In plants with intermediate dosage (two) of the somatic-association suppressor, the sensitivity is not linearly related to the colchicine concentration.

In summary, the results presented indicate clearly that the somatic-association genes affect quantitatively some of the characteristics of the spindle. The somaticassociation suppressor tends to reduce spindle affinity for colchicine so that the spindle is less sensitive to this substance, and its function is not inhibited completely even by relatively high concentrations. On the other hand, the somaticassociation promoter increases spindle sensitivity to colchicine.

\section{DISCUSSION}

Isolation of the spindle microtubules for a comparative study of their chemical and physical properties is an extremely difficult task. As yet, spindle microtubules of plants have not been successfully isolated. The spindle system is very sensitive and labile (INoue and SATo 1967). It is therefore quite likely that direct isolation would affect many of its native properties. Some of the significant differences that 
might exist between spindle microtubules of different genotypes could be disturbed or completely eliminated. Accordingly, it seems that a comparative analysis of the spindle microtubules of different genotypes in vivo would be a more reliable approach. In this work, the binding ability in vivo of the spindle microtubules to colchicine was used as a criterion for the comparison of the microtubules of the several genotypes.

The microtubules of the spindle fibers exist in a dynamic equilibrium with their subunits (INoue 1959, 1960, 1964). This equilibrium can be disturbed and shifted towards dissociation by binding the subunits with colchicine (BorIsY and Taylor 1967). Weisenberg, Borisy and Taylor (1968) have concluded that the binding of colchicine is a specific property of the protein subunits of microtubules. The rate of this binding is proportional to colchicine concentration (TAYLOR 1965). In the present study, the degree of affinity of the microtubular subunit for colchicine was used to compare the microtubules of plants having different dosages of the somatic-association genes. The effect of colchicine on the depolymerization of the spindle microtubules in the different genotypes was determined by observing the disturbances in spindle formation and function during cell division.

The data showed clearly that the affinity of spindle microtubular subunits for colchicine is significantly decreased with increasing dosage of the somatic-association suppressor on $5 \mathrm{~B}^{\mathrm{L}}$. The microtubules of plants with zero doses of $5 \mathrm{~B}^{\mathrm{L}}$ were most sensitive, while those of plants having two or four doses of this chromosomal arm were less and least sensitive, respectively. The disruption of microtubules in plants having four doses of $5 \mathrm{~B}^{\mathrm{L}}$ was not complete even at very high concentrations of colchicine. It appears that the somatic-association suppressor inhibits the capability of microtubule subunits to bind colchicine.

On the other hand, the somatic-association promoter on the short arm of chromosome $5 \mathrm{~B}\left(5 \mathrm{~B}^{\mathrm{s}}\right)$, seems to increase the depolymerization of spindle microtubules produced by colchicine. The affinity for colchicine was higher in plants with two doses of $5 \mathrm{~B}^{\mathrm{S}}$ than in plants deficient for this chromosomal arm. As expected, the effect of the $5 \mathrm{~B}^{\mathrm{s}}$ promoter on spindle affinity for colchicine is opposite to, and somewhat weaker than, that of the suppressor. This is in accord with the suggestion that there are several somatic-association promoters in common wheat, each having a weak effect on the degree of association of homologous chromosomes (FELDMAN 1968). The total effect of all the promoters counteracts the strong effect of the single suppressor.

It might be argued that the somatic-association suppressor does not inhibit the ability of the subunit to bind colchicine but that this gene decreases membrane permeability to compounds from the outer media. This explanation is untenable, for if only permeability were involved, high levels of spindle disruption should have been obtainable in plants with four doses of the suppressor simply by raising the colchicine concentration. This was not the case, as spindle disruption in such plants reached a relatively low maximum that did not respond to further increases in colchicine concentration. Preliminary experiments showed that lengthening the time of treatment is also ineffective in di-isosomic $5 \mathrm{~B}^{\mathrm{L}}$ plants in raising the maximum spindle disruption. 
The somatic-association suppressor can affect the ability of the subunit to bind colchicine by two possible mechanisms: (a) it can affect the rate of polymerization of the microtubular protein; (b) it can alter the primary structure or the allosteric conformation of the subunit.

At present, there is no conclusive evidence for either mechanism. However, it seems more reasonable to assume that this gene is responsible for the structure of the subunit. The structurally modified subunit apparently has a lower capacity for binding colchicine.

Plants deficient for the suppressor exhibited a linear correlation between colchicine concentration and the degree of spindle disruption. This accords well with the results of TAYLOR (1965) who found that colchicine was bound to the cell at a rate proportional to its concentration. It is interesting to note therefore, that in plants having two doses of the suppressor, where there is a balance between the effect of the suppressor and that of several promoters, the correlation between colchicine concentration and spindle disruption is not linear. This nonlinearity may suggest that there are at least two types of subunits, normal and structurally modified, which have different affinities for colchicine. Plants deficient for the suppressor presumably have only the normal type of subunit and therefore exhibit a linear correlation between colchicine concentration and spindle disruption. In plants with four doses of $5 \mathrm{~B}^{\mathrm{L}}$, the effect of colchicine concentration was also approximately linear. In this genetic combination, it is assumed that the modified subunit is quantitatively dominant.

It was shown earlier by Feldman (1966) that the somatic-association suppressor has a dosage effect on the association of homologous chromosomes in somatic cells. The results of the present study on the dosage effect of this gene on spindle sensitivity to colchicine support FeLDMAN's conclusion. The hypothesis that the suppressor alters the subunit structure is offered to explain this dosage effect of $5 \mathrm{~B}^{\mathrm{L}}$. Plants with different doses of $5 \mathrm{~B}^{\mathrm{L}}$ would have different proportions of normal and modified subunits.

Any suggestion at the present time as to how the suppressor reduces the association of homologous chromosomes in somatic cells through modification of the dynamic system of the microtubules would be purely speculative. This modification can either affect the rate of spindle microtubules assembly and disassembly or the specifity which exists between centromeres, chromosomal spindle fibers and pole areas. In either case, the effect would lead to disorder, and a random distribution of centromeres at the poles.

Financial assistance from the National Research Council of Canada is gratefully acknowledged.

\section{SUMMARY}

The association of homologous chromosomes in somatic cells of common wheat, Triticum aestivum L., is regulated by genes which apparently affect the functional characteristics of the spindle system. It was found that in dividing root-tip cells, spindle sensitivity to colchicine decreased with increased dosage (from zero to four) of the somatic-association suppressor located on the long arm of chromosome 5B. On the other hand, increasing the dosage (from zero to two) 
of one of the somatic-association promoters (located on the short arm of chromosome $5 \mathrm{~B}$ ) increases the spindle sensitivity to colchicine. It was concluded that the somatic-association genes regulate somatic association by affecting some of the characteristics of the spindle microtubular protein. The somatic-association suppressor inhibits the affinity of the spindle microtubular subunits for colchicine. It is postulated that this gene alters the structure of the spindle subunits or their rate of polymerization.

\section{LITERATURE CITED}

Adelmai, M. R., G. G. Borisy, M. L. Stelanski, R. C. Weisenberg and E. W. Taylor, 1968 Cytoplasmic filaments and tubules. Federation Proc. 27 : 1186-1193.

Avivi, L., M. Feldman and W. Bushum, 1969 The mechanism of somatic association in common wheat, Triticum aestivum L. I. Suppression of somatic association by colchicine. Genetics 62: 745-752.

BorisY, G. G. and E. W. TAYLOR, 1967 The mechanism of action of colchicine. Colchicine binding to sea urchin eggs and the mitotic apparatus. J. Cell Biol. 34: 535-548.

Feldman, M., 1966 The effect of chromosomes 5B, 5D and 5A on chromosomal pairing in Triticum aestivum. Proc. Natl. Acad. Sci. U.S. 55: 1447-1453. ——, 1968 Regulation of somatic association and meiotic pairing in common wheat. Proc. Intern. Wheat Genet. Symp. 3: 31-40.

Feldman, M., T. Mejlo-Sampayo and E. R. Sears, 1966 Somatic association in Triticum aestivum. Proc. Natl. Acad. Sci. U.S. 56: 1192-1199.

Inoue, S., 1959 Motility of cilia and the mechanism of mitosis. Rev. Med. Physiol. 31 : 402-408. $\longrightarrow 1960$ On the physical properties of the mitotic spindle. Ann. N.Y. Acad. Sci. 90: 529. —- 1964 Organization and function of the mitotic spindle. pp. 549-598. In: Primitive Motile Systems in Cell Biology. Edited by R. D. Alren and N. KamrYa. Academic Press, New York.

InouE, S. and H. SATo, 1967 Cell motility by labile association of molecules. The nature of mitotic spindle fibers and their role in chromosome movement. J. Gen. Physiol. 50 : 259-292.

LEDBETrER, M. C., 1967 The disposition of microtubules in plant cells during interphase and mitosis. In: Formation and Fate of Cell Organelles. Symp. Intern. Soc. Cell Biol. 6: 55-70.

TAYLOR, E. W., 1965 The mechanism of colchicine inhibition of mitosis. I. Kinetics of inhibition and the binding of $\mathrm{H}^{3}$-colchicine. J. Cell Biol. 25: 145-160.

Weisengerg, R. C., G. G. Borrsy and E. W. TAYLor, 1968 The colchicine-binding protein of a mammalian brain and its relation to microtubules. Biochemistry $7: 4466-4479$. 